\title{
The energy-saving effect of a new myosin activator, omecamtiv mecarbil, on LV mechanoenergetics in rat hearts with blood-perfused isovolumic contraction model
}

\author{
Koji Obata ${ }^{1} \cdot$ Hironobu Morita ${ }^{1} \cdot$ Miyako Takaki $^{1}$ \\ Received: 13 July 2018 / Accepted: 26 June 2019 / Published online: 2 July 2019 \\ (C) The Author(s) 2019
}

\begin{abstract}
A novel myosin activator, omecamtiv mecarbil (OM), is a cardiac inotropic agent with a unique new mechanism of action, which is thought to arise from an increase in the transition rate of myosin into the actin-bound force-generating state without increasing calcium $\left(\mathrm{Ca}^{2+}\right)$ transient. There remains, however, considerable controversy about the effects of OM on cardiac contractility and energy expenditure. In the present study, we investigated the effects of OM on left ventricular (LV) mechanical work and energetics, i.e., mechanoenergetics in rat normal hearts (CTL) and failing hearts induced by chronic administration of isoproterenol $(1.2 \mathrm{mg} / \mathrm{kg} / \mathrm{day}$ ) for 4 weeks (ISO-HF). We analyzed the LV end-systolic pressure-volume relation (ESPVR) and the linear relation between the myocardial oxygen consumption per beat $\left(\mathrm{VO}_{2}\right)$ and systolic pressure-volume area $(\mathrm{PVA}$; a total mechanical energy per beat) in isovolumically contracting rat hearts at 240- or 300-bpm pacing in the absence or presence of OM. OM did not change the ESPVR in CTL and ISO-HF. OM, however, significantly decreased the slope of $\mathrm{VO}_{2}-\mathrm{PVA}$ relationship in both CTL and ISO-HF, and significantly increased the mean $\mathrm{VO}_{2}$ intercept without changes in basal metabolism in ISO-HF. These results suggested that OM improved the oxygen cost of PVA (contractile efficiency) with the unchanged LV contractility in both CTL and ISO-HF but increased $\mathrm{VO}_{2}$ for $\mathrm{Ca}^{2+}$ handling in excitation-contraction (E-C) coupling in ISO-HF. We concluded that OM improves contractile efficiency in normal and failing hearts but increases $\mathrm{O}_{2}$ consumption of $\mathrm{Ca}^{2+}$ handling in failing hearts in isovolumically contracting rat model.
\end{abstract}

Keywords Myosin activator $\cdot$ Excitation-contraction coupling $\cdot$ Oxygen consumption $\cdot$ Pressure-volume area, heart failure

$\begin{array}{ll}\text { Abbreviations } \\ \mathrm{OM} & \text { Omecamtiv mecarbil } \\ \mathrm{LV} & \text { Left ventricle } \\ \mathrm{ESPVR} & \text { End-systolic pressure-volume relation } \\ \mathrm{VO}_{2} & \text { Myocardial oxygen consumption per beat } \\ \mathrm{PVA} & \text { Pressure-volume area } \\ \mathrm{bpm} & \text { Beats per minute } \\ \mathrm{E}-\mathrm{C} & \text { Excitation-contraction } \\ \text { Emax } & \text { Maximum elastance } \\ \mathrm{mLVV} & \text { Midrange LV volume }\end{array}$

Electronic supplementary material The online version of this article (https://doi.org/10.1007/s00210-019-01685-4) contains supplementary material, which is available to authorized users.

Koji Obata

obatak@gifu-u.ac.jp

1 Department of Physiology, Gifu University Graduate School of Medicine, 1-1 Yanagido, Gifu 501-1194, Japan

$\begin{array}{ll}\text { ANCOVA } & \text { Analysis of covariance } \\ \text { EDPVR } & \text { End-diastolic pressure-volume relation } \\ \text { ESP }_{\mathrm{mLVV}} & \text { End-systolic pressure at mLVV } \\ \mathrm{PVA}_{\mathrm{mLVV}} & \text { PVA at mLVV } \\ \mathrm{KCl} & \text { Potassium chloride } \\ \mathrm{SV} & \text { Stroke volume } \\ \text { SET } & \text { Systolic ejection time } \\ \text { ATPase } & \text { Sarcoplasmic reticulum } \mathrm{Ca}^{2+} \\ \text { SERCA } & \mathrm{SR} \mathrm{Ca}^{2+} \text { ATPase } \\ \text { SR } & \mathrm{Sarcoplasmic} \mathrm{reticulum}^{2+} \\ \text { NCX } & \mathrm{Na}^{+} / \mathrm{Ca}^{2+} \text { exchanger }\end{array}$

\section{Introduction}

In pharmacotherapy for heart failure, the conventional inotropic drugs such as digitalis, $\beta$-agonist, and phosphodiesterase inhibitors were sought to enhance the calcium $\left(\mathrm{Ca}^{2+}\right)$ handling for activating contractions. Thus, such drugs increased in myocardial 
energy expenditure and the consequently increased energy expenditure can worsen a patient's prognosis in heart failure from a long-term perspective (Bers and Harris 2011).

A novel cardiac myosin activator, omecamtiv mecarbil (OM), has been reported to exert a positive inotropic action by accelerating the transition rate of myosin into the strongly actin-bound force-generating state, and decreasing the rate of actinindependent phosphate release, i.e., reducing non-productive and hence wasteful hydrolysis of ATP, without enhancing intracellular $\mathrm{Ca}^{2+}$ load (Teerlink 2009; Malik et al. 2011). Thus, theoretically, this drug can enhance cardiac output without increasing energy expenditure unlike conventional inotropic drugs. Previous studies reported that $\mathrm{OM}$ did not change minimum $\mathrm{dP} / \mathrm{dt}$, an index of diastolic function in vivo (Shen et al. 2010; Malik et al. 2011). On the other hand, in vitro, OM increased the relaxation time of cardiomyocytes (Horváth et al. 2017). The effects of $\mathrm{OM}$ on diastolic function and energy consumption remain controversial. Shen et al. (2010) demonstrated that chronic infusion of OM improved left ventricular (LV) function without increasing myocardial $\mathrm{O}_{2}$ consumption $\left(\mathrm{MVO}_{2}\right)$ in systolic heart failure canine model. In contrast, Bakkehaug et al. (2015) reported that OM lead to reduced contractile efficiency and increased energy expenditure as mediated by hyperactivity in resting myosin ATPase in both of contractile and non-contractile of the hearts in mice and pigs. In addition, they showed that $\mathrm{OM}$ increased $\mathrm{MVO}_{2}$ for basal metabolism in ex vivo mice hearts with unchanged $\mathrm{MVO}_{2}$ for excitation-contraction (E-C) coupling. There are obvious discrepancies among these OM effects on cardiac function and energy expenditure, although these were reported from different animal hearts.

In the present study, we would clarify the effects of OM on the relationship between mechanical work and energy consumption using equivalent Emax (eEmax)-pressure-volume area (PVA) $-\mathrm{VO}_{2}$ framework to analyze $\mathrm{LV}$ mechanics and energetics, i.e., mechanoenergetics, in rat normal and failing hearts using an excised, blood-perfused whole heart preparation (Takaki 2004).

\section{Methods}

\section{Experimental animals}

Isoproterenol-induced heart failure as failing hearts (ISO-HF) made as previously reported (Shibata et al. 2011; Mitsuyama et al. 2013) and normal hearts as control (CTL) were used in the present study.

\section{Excised cross-circulated rat heart model and data analysis}

The excised cross-circulated rat heart model was described in detail in the Online supplements (supplemental Fig. 1). OM infused at a final concentration about $200-500 \mathrm{ng} / \mathrm{mL}$ into coronary circulation. Data analysis obtained from this experimental model was also described in detail in the Online supplements (supplemental Fig. 2).

\section{Analyses of one-beat LV pressure-time curve by a logistic function}

To evaluate LV end-diastolic relaxation rate or lusitropism, we used the logistic time constant derived from a logistic model to analyze LV isovolumic relaxation pressure-time curve at midrange LV volume (mLVV) (Mitsuyama et al. 2013).

\section{Statistics}

We compared the $\mathrm{VO}_{2}-\mathrm{PVA}$ regression lines of the volume runs between pre- and post-OM treatment in each heart by analysis of covariance (ANCOVA). Comparison of paired and unpaired individual values was performed by paired and unpaired $t$ test, respectively. A value of $p<0.05$ or $p<0.01$ was considered statistically significant. All data are expressed as the mean \pm S.D.

\section{Results}

\section{Effects of OM on LV contractility in the CTL and ISO-HF}

OM showed that both of LV ESPVRs and end-diastolic pressure-volume relations (EDPVRs) did not change in both CTL and ISO-HF (Fig. 1a). In fact, the mean ESP $\mathrm{mLVV}_{\text {and }}$ PVA $_{\mathrm{mLVV}}(n=6$, each) in ISO-HF showed significant decreases compared with those in CTL but did not show significant differences between pre- and post-OM treatment (Fig. 1d and e). The coronary blood flows were not significantly different between both CTL and ISO-HF in the absence or presence of OM (data not shown).

\section{Effects of $\mathrm{OM}$ on $\mathrm{VO}_{2}$-PVA relations in the CTL and ISO-HF}

$\mathrm{OM}$ treatment decreased the slopes of $\mathrm{VO}_{2}-\mathrm{PVA}$ linear relations in both of CTL and ISO-HF (Fig. 1b and c) and elevated the $\mathrm{VO}_{2}$ intercepts of $\mathrm{VO}_{2}-\mathrm{PVA}$ linear relations exclusively in ISO-HF (Fig. 1c). In comparisons by paired $t$ test between pre-

Fig. 1 Representative data of ESPVRs and EDPVRs (a), and $\mathrm{VO}_{2}-\mathrm{PVA}$ relations in pre- and post-OM treated same hearts in CTL (b) and ISO-HF (c), respectively. The comparison of $\operatorname{ESP}_{\mathrm{mLVV}}(\mathbf{d}), \mathrm{PVA}_{\mathrm{mLVV}}(\mathbf{e})$, slope (f), and $\mathrm{VO}_{2}$ intercepts (g), and the means $\mathrm{VO}_{2}$ for E-C coupling (h) and $\mathrm{O}_{2}$ consumption for basal metabolism (i) at the pre- and post-OM treatments in CTL ( $n=5-6$ each) and ISO-HF ( $n=4-6$ each). Values are mean $\pm \mathrm{SD}$ (h and i). ${ }^{*} P<0.01$, pre-OM vs. post-OM. ${ }^{\#} P<0.05$, CTL vs. ISO-HF 
and post-OM treatments, the mean slopes were significantly decreased in both CTL and ISO-HF ( $P<0.01$, Fig. 1f). The mean $\mathrm{VO}_{2}$ intercepts were significantly increased in ISO-HF

$(P<0.01$, Fig. $1 \mathrm{~g})$ but not in CTL. These results indicate that a

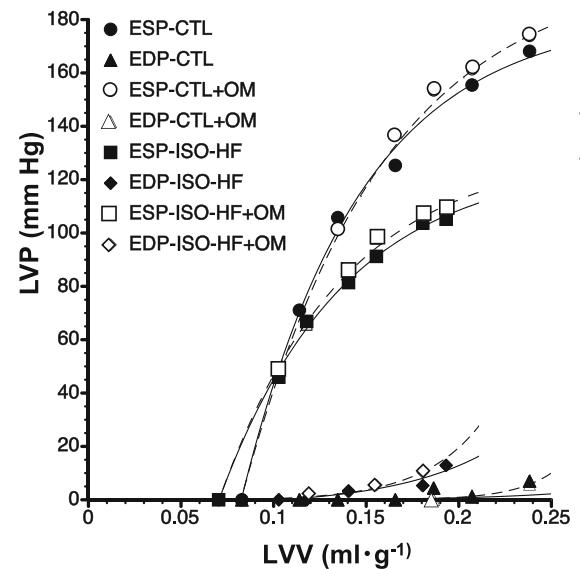

$\operatorname{LVV}\left(\mathrm{ml} \cdot \mathrm{g}^{-1)}\right.$

d

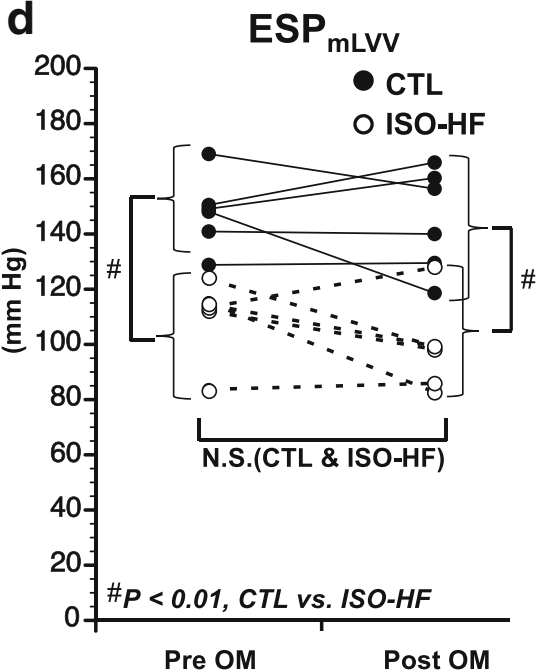

g

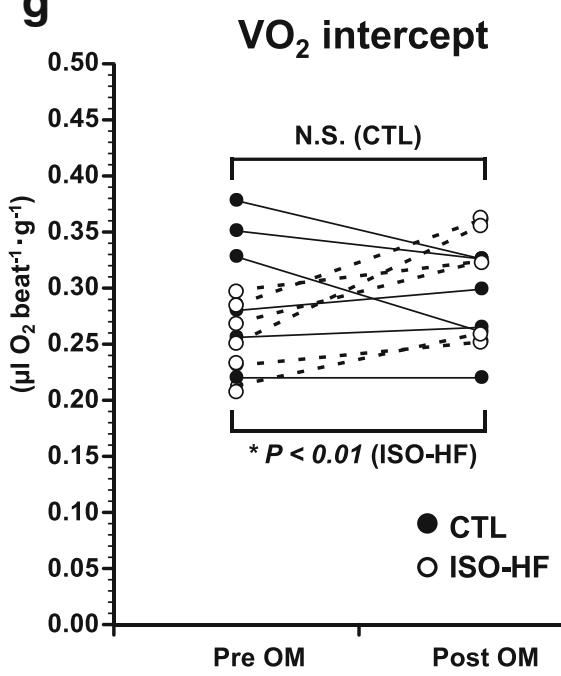

b

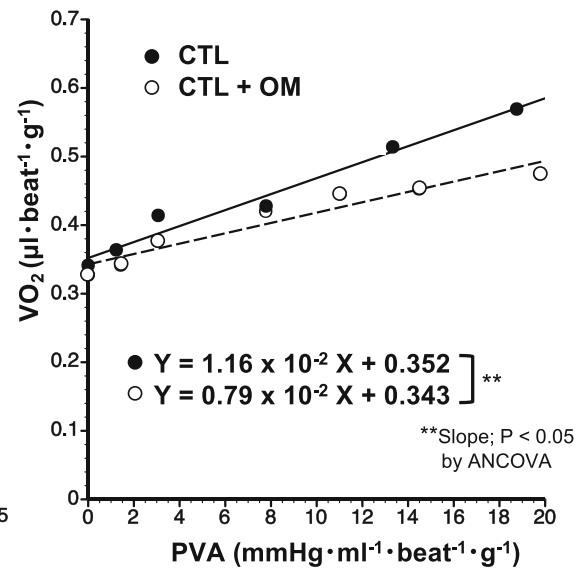

e

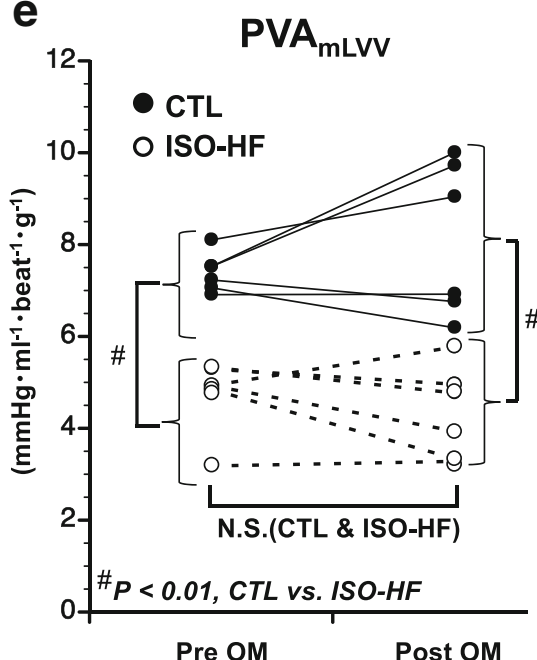

h

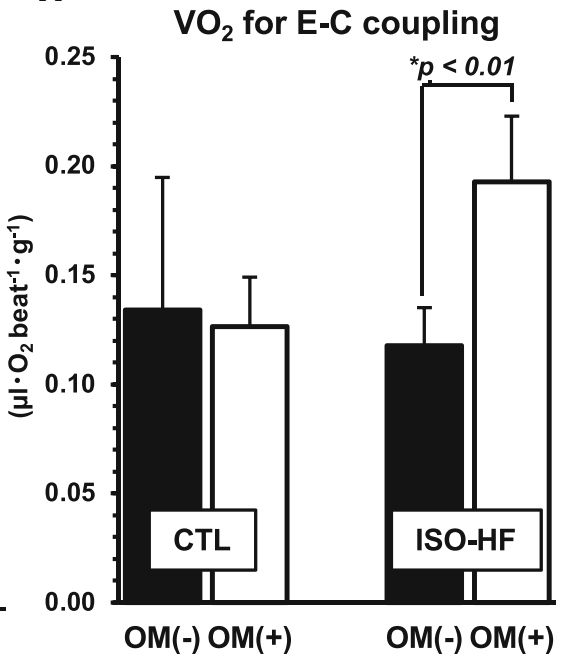

C $\mathrm{VO}_{2}$-PVA relation (ISO-HF)

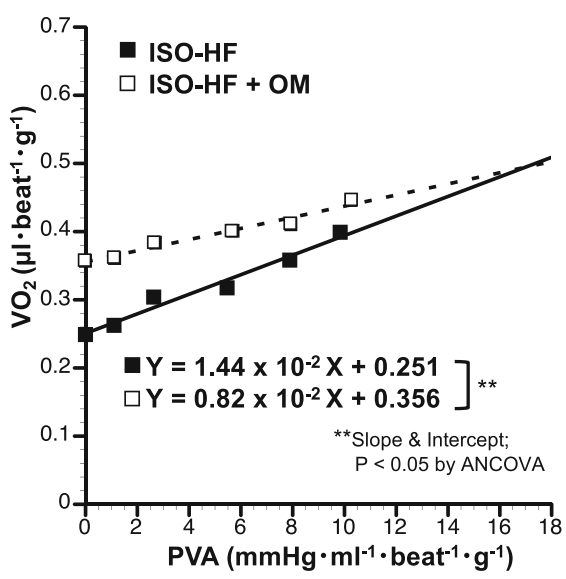

f

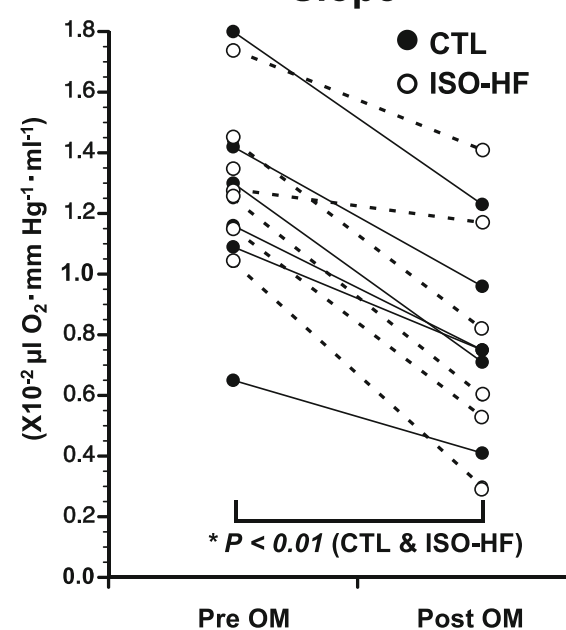

i

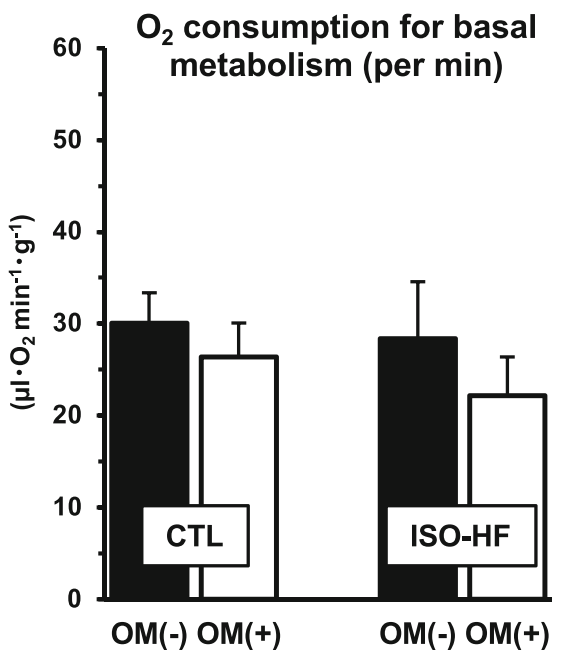


Fig. 2 Representative data of normalized pressure-time curves at $\mathrm{mLVV}$ in the CTL at $300 \mathrm{bpm}$ (a), 240 bpm (b) pacing, and ISO$\mathrm{HF}$ (c) at 240-bpm pacing in the absence (closed circle) and the presence (opened circle) of OM $(289-316 \mathrm{ng} / \mathrm{mL}$ in the blood). The comparison of the mean logistic time constants at mLVV in the CTL at 300-bpm pacing ( $n=$ 8), 240-bpm pacing $(n=7)$, and ISO-HF at 240-bpm pacing ( $n=$ 8 ) in the absence (solid column) and presence of OM (open column) $(211-357 \mathrm{ng} / \mathrm{mL}$ in the blood) (d). Values are mean $\pm \mathrm{SD}$ ${ }^{*} P<0.01,{ }^{\#} P<0.05, \mathrm{OM}(+)$ vs. $\mathrm{OM}(-)$
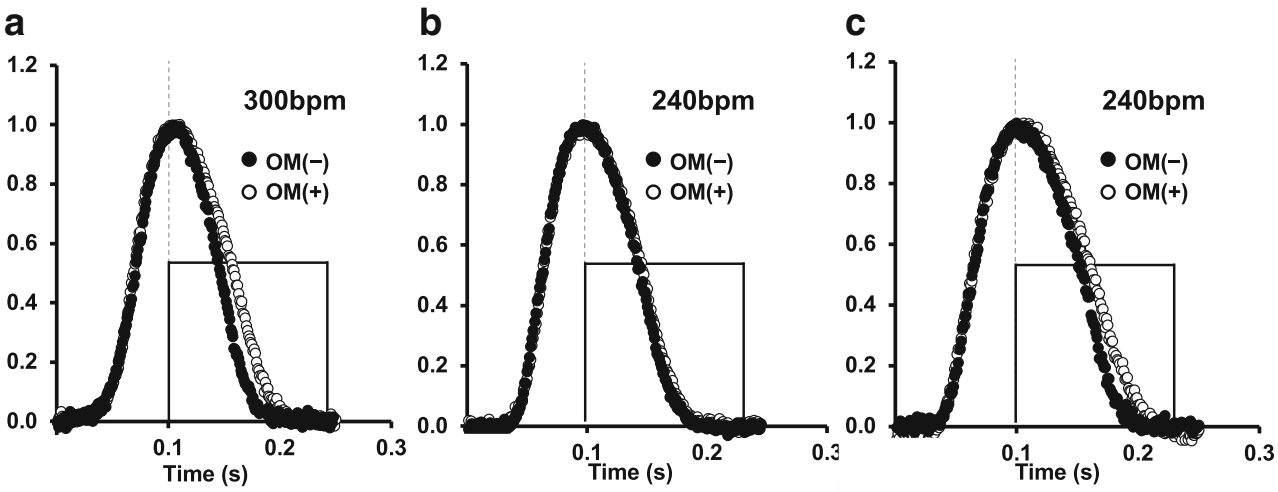

d

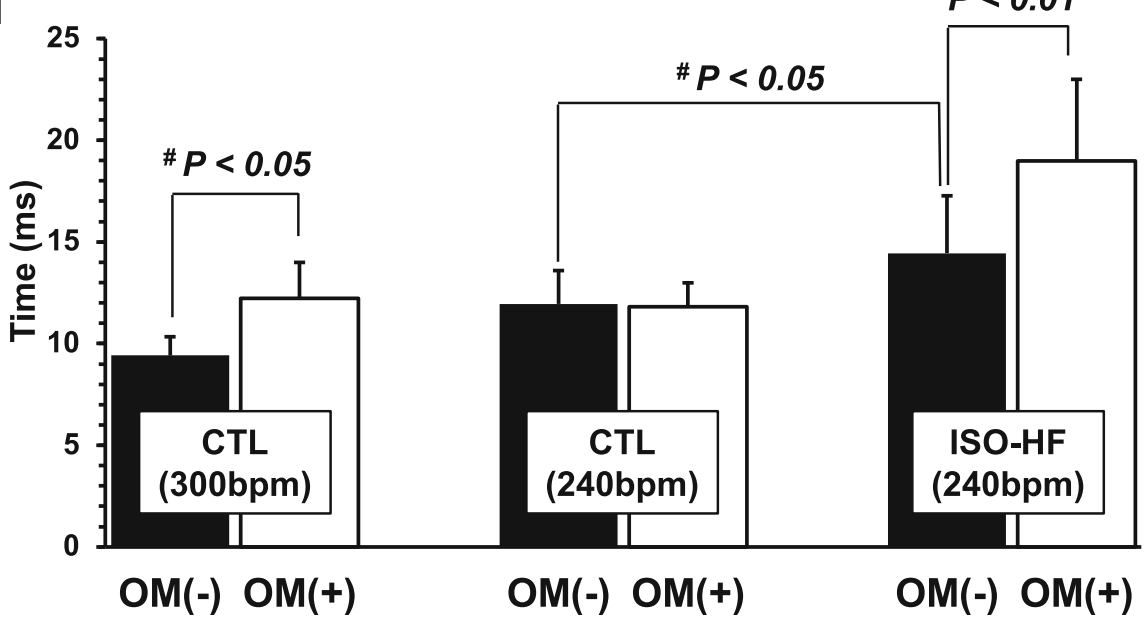

OM markedly improves the cost of PVA or its reciprocal shows contractile efficiency, i.e., the energy transduction rate of mechanical work per ATP.

\section{Effects of $\mathrm{OM}$ on $\mathrm{O}_{2}$ consumptions for E-C coupling and basal metabolism in the CTL and ISO-HF}

To clarify the mechanisms of the increased $\mathrm{VO}_{2}$ intercepts in OM-treated ISO-HF, we performed cardiac arrest by $\mathrm{KCl}$ infusion to obtain $\mathrm{O}_{2}$ consumption for basal metabolism. OM treatment did not change the $\mathrm{O}_{2}$ consumption for basal metabolism in both of CTL and ISO-HF (Fig. 1i) but significantly increased the $\mathrm{VO}_{2}$ for E- $\mathrm{C}$ coupling exclusively in ISO-HF $(P<0.01$, Fig. 1h). These results indicate that $\mathrm{OM}$ increases $\mathrm{VO}_{2}$ intercepts mediated via the increase of $\mathrm{VO}_{2}$ for $\mathrm{E}-\mathrm{C}$ coupling in ISO-HF.

\section{Effects of OM on lusitropism in the CTL and ISO-HF}

We compared the normalized LV pressure-time curves and logistic time constants between pre- and post-OM treatments in the same hearts of each of CTL and ISO-HF to reveal the effects of OM on LV lusitropism. OM prolonged the duration of LV relaxation time in a CTL at 300-bpm pacing (Fig. 2a) and an ISO-HF at 240-bpm pacing (Fig. 2c) but not in a CTL at 240-bpm pacing (Fig. 2b). The mean post-OM logistic time constants elongated in both CTL at $300-\mathrm{bpm}$ pacing $(P<0.05)$ and ISO-HF at $240-$ bpm pacing $(P<0.01)$ but not in CTL at 240-bpm pacing (Fig. 2d).

\section{Discussion}

In the present study, we found that the administration of $\mathrm{OM}$ did not change the ESPVR and EDPVR, ESP, and PVA at $\mathrm{mLVV}$ in both of CTL and ISO-HF, indicating that OM does not affect the LV contractility in both normal and failing hearts. Previous in vivo studies showed that OM improved stroke volume (SV) and cardiac output related to the extension of systolic ejection time (SET) in rat or canine failing hearts (Malik et al. 2011; Shen et al. 2010; Malik and Morgan 2011). In addition, Bakkehaug et al. (2015) reported that the OM increased cardiac output through the extension of SET in swine failing hearts. These results suggested that OM would exert positive inotropic effects by extending the SET without changing cardiac contractility. The results from clinical trials 
showing OM significantly increases SET in a dose-dependent manner in both healthy volunteers and patients with systolic heart failure (Cleland et al. 2011; Teerlink et al. 2011) might support this suggestion.

The most significant effect of OM would be an enhancing cardiac function without increasing intracellular $\mathrm{Ca}^{2+}$ and energy expenditure unlike conventional inotropic drugs. Shen et al. reported that $\mathrm{OM}$ treatment increased stroke work over $60 \%$ with no increase in $\mathrm{O}_{2}$ demand, resulting in a 25-30\% increase in cardiac efficiency (Teerlink 2009; Shen et al. 2010). In contrast, Bakkehaug et al. (2015) reported that OM decreased the contractile efficiency evaluated by the reciprocal of the slope of PVA- $\mathrm{MVO}_{2}$ linear relation with the unchanged stroke work, indicating that OM leads to significant $\mathrm{O}_{2}$ waste. In addition, $\mathrm{OM}$ increased basal metabolic $\mathrm{VO}_{2}$. In the present study, our experimental model has an isovolumic contracting hearts without ejection, i.e., no cardiac output, which is a possible reason for giving the discrepancy from previous studies. We found that $\mathrm{OM}$ obviously improves the contractile efficiency in both normal and failing hearts with the unchanged ESPVR, indicating that OM leads to apparent $\mathrm{O}_{2}$ saving with the unchanged LV contractility (Fig. 1a, $\mathrm{d}-\mathrm{f})$. This discrepancy in the effects of OM on contractile efficiency might be generated by the difference among experimental models. In the present study, the reason why OM decreased $\mathrm{O}_{2}$ consumption in spite of the unchanged PVA at the same preload is still unknown. OM might have decreased the increasing rate of the number of myosin head binding actin filaments and/or reduced non-productive ATP hydrolysis (the rate of actin-independent phosphate release) under increasing LVV in isovolumic contracting hearts. In addition, the effects of OM on contractile efficiency appear to exert in both normal and failing hearts regardless of cardiac myosin isoform. Because it is well known that myosin isoform shift, for example, from the faster alpha-myosin isoform to slower betamyosin isoform in rodents occurs in failing hearts. Our recent study demonstrated that the slope of $\mathrm{VO}_{2}-\mathrm{VA}$ relations in the hearts of cardiac sarcoplasmic reticulum $\mathrm{Ca}^{2+}$ ATPase (SERCA) 2a-overexpressed transgenic rats significantly smaller than that in wild-type rats, which indicates that the increased SERCA protein improved the efficiency of chemo-mechanical energy transduction (Zhang et al. 2012). Thus, the interaction between $\mathrm{Ca}^{2+}$ handling in $\mathrm{E}-\mathrm{C}$ coupling and cross-bridge cycling may be related to the mechanism providing contractile efficiency.

Recently, it was reported that OM increased the open probability of ryanodine receptor channel and the $\mathrm{Ca}^{2+}$ sensitivity of force production (Nánási et al. 2017; Nagy et al. 2015), suggesting that a $\mathrm{Ca}^{2+}$ leak from the sarcoplasmic reticulum (SR) may modify the inotropic effect of OM. On the other hand, OM did not increase the $\mathrm{Ca}^{2+}$ transient though it increased rat and canine cardiac myocyte shortening (Malik et al. 2011; Horváth et al. 2017) and OM did not change the
$\mathrm{VO}_{2}$ for $\mathrm{Ca}^{2+}$ handling in $\mathrm{E}-\mathrm{C}$ coupling in ex vivo mouse hearts (Bakkehaug et al. 2015). In the present study, we found that the $\mathrm{VO}_{2}$ for $\mathrm{Ca}^{2+}$ handling in $\mathrm{E}-\mathrm{C}$ coupling was increased in ISO-HF but not CTL after OM treatment (Fig. 1h). This increase might be related to the deterioration of $\mathrm{Ca}^{2+}$ uptake due to the SERCA2a downregulation in failing hearts. The increased intracellular $\mathrm{Ca}^{2+}$ with a $\mathrm{Ca}^{2+}$ leak from SR by $\mathrm{OM}$ is dominantly removed from the cytosol via $\mathrm{Na}^{+} / \mathrm{Ca}^{2+}$ exchanger (NCX), rather than $\mathrm{Ca}^{2+}$ uptake via the SERCA2a to SR. Although NCX per se does not consume ATP to remove cytosolic $\mathrm{Ca}^{2+}$ in exchange with $\mathrm{Na}^{+}$influx (stoichiometry of $3 \mathrm{Na}^{+}: 1 \mathrm{Ca}^{2+}$ ), $\mathrm{Na}^{+}$influx must be pumped out by $\mathrm{Na}^{+} / \mathrm{K}^{+}$-ATPase, with a stoichiometry of $3 \mathrm{Na}^{+}: 2 \mathrm{~K}^{+}: 1 \mathrm{ATP}$, resulting in the net stoichiometry of $1 \mathrm{Ca}^{2+}: 1 \mathrm{ATP}$. In contrast, SERCA2a removes cytosolic $\mathrm{Ca}^{2+}$ based on stoichiometry of $2 \mathrm{Ca}^{2+}: 1 \mathrm{ATP}$ (Takaki 2004; Mitsuyama et al. 2013). Thus, it is a possible mechanism that $\mathrm{OM}$ increased the $\mathrm{VO}_{2}$ in $\mathrm{E}-\mathrm{C}$ coupling only in failing hearts.

$\mathrm{OM}$ significantly increased in LV relaxation time in failing hearts at 240-bpm pacing (higher 240-bpm pacing is impossible in failing hearts) or CTL at 300-bpm pacing, which would be associated with the impaired extrusion of the increased intracellular $\mathrm{Ca}^{2+}$ from the cytosol (Fig. 2). Recently, Horváth et al. (2017) demonstrated that high-frequency pacing in the presence of OM and/or high concentration of OM decreased canine cardiomyocyte shortening and OM dose-dependently prolonged canine cardiomyocyte relaxation time with the unchanged $\mathrm{Ca}^{2+}$ transient amplitude. These results suggest that any hearts with a higher heart rate, especially in diastolic dysfunction, would be susceptible to any detrimental effects of OM.

Finally, we concluded that OM improved the efficiency for converting chemical energy into mechanical work with the unchanged LV contractility in isovolumic contracting rat heart model. In the present failing hearts, $\mathrm{OM}$ increased the $\mathrm{VO}_{2}$ for $\mathrm{Ca}^{2+}$ handling in E-C coupling. Therefore, upon the clinical application of OM, we must perform a careful pharmacotherapy for the patients with higher heart rate, i.e., tachycardia, and/or with diastolic dysfunction, to be sufficient for the ventricular filling and the coronary flow.

Author contributions $\mathrm{KO}$ and MT conceived and designed research. KO conducted experiments and obtained the data. HM and MT supervised the present study. KO and MT performed the data analysis and drafted the manuscript.

Funding information This work was supported in part by grants-in-aid nos. 22790216 and 25460283 for the Scientific Research from the Ministry of Education, Culture, Sports, Science and Technology of Japan and by Novartis Pharma Research Grants to K.O.

\section{Compliance with ethical standards}

Conflict of interest The authors declare that they have no of conflict of interest. 
Open Access This article is distributed under the terms of the Creative Commons Attribution 4.0 International License (http:// creativecommons.org/licenses/by/4.0/), which permits unrestricted use, distribution, and reproduction in any medium, provided you give appropriate credit to the original author(s) and the source, provide a link to the Creative Commons license, and indicate if changes were made.

\section{References}

Bakkehaug JP, Kildal AB, Engstad ET, Boardman N, Næsheim T, Rønning L, Aasum E, Larsen TS, Myrmel T, How OJ (2015) Myosin activator omecamtiv mecarbil increases myocardial oxygen consumption and impairs cardiac efficiency mediated by resting myosin ATPase activity. Circ Heart Fail 8:766-775. https://doi.org/ 10.1161/CIRCHEARTFAILURE.114.002152

Bers DM, Harris SP (2011) Translational medicine: to the rescue of the failing heart. Nature 473:36-39. https://doi.org/10.1038/473036a

Cleland JG, Teerlink JR, Senior R, Nifontov EM, Mc Murray JJ, Lang CC, Tsyrlin VA, Greenberg BH, Mayet J, Francis DP, Shaburishvili T, Monaghan M, Saltzberg M, Neyses L, Wasserman SM, Lee JH, Saikali KG, Clarke CP, Goldman JH, Wolff AA, Malik FI (2011) The effects of the cardiac myosin activator, omecamtiv mecarbil, on cardiac function in systolic heart failure: a double-blind, placebocontrolled, crossover, dose-ranging phase 2 trial. Lancet 378:676683. https://doi.org/10.1016/S0140-6736(11)61126-4

Horváth B, Szentandrássy N, Veress R, Almássy J, Magyar J, Bányász TA, Papp Z, Nánási PP (2017) Frequency-dependent effects of omecamtiv mecarbil on cell shortening of isolated canine ventricular cardiomyocytes. Naunyn Schmiedeberg's Arch Pharmacol 390: 1239-1246. https://doi.org/10.1007/s00210-017-1422-z

Malik FI, Morgan BP (2011) Cardiac myosin activation part 1: from concept to clinic. J Mol Cell Cardiol 51:454-461. https://doi.org/ 10.1016/j.yjmcc.2011.05.006

Malik FI, Hartman JJ, Elias KA, Morgan BP, Rodriguez H, Brejc K, Anderson RL, Sueoka SH, Lee KH, Finer JT, Sakowicz R, Baliga R, Cox DR, Garard M, Godinez G, Kawas R, Kraynack E, Lenzi D, Lu PP, Muci A, Niu C, Qian X, Pierce DW, Pokrovskii M, Suehiro I, Sylvester S, Tochimoto T, Valdez C, Wang W, Katori T, Kass DA, Shen YT, Vatner SF, Morgans DJ (2011) Cardiac myosin activation: a potential therapeutic approach for systolic heart failure. Science 331:1439-1443. https://doi.org/10.1126/science.1200113
Mitsuyama S, Takeshita D, Obata K, Zhang GX, Takaki M (2013) Left ventricular mechanical and energetic changes in long-term isoproterenol-induced hypertrophied hearts of SERCA2a transgenic rats. J Mol Cell Cardiol 59:95-106. https://doi.org/10.1016/j.yjmcc.2013. 02.012

Nagy L, Kovács Á, Bódi B, Pásztor ET, Fülöp GÁ, Tóth A, Édes I, Papp Z (2015) The novel cardiac myosin activator omecamtiv mecarbil increases the calcium sensitivity of force production in isolated cardiomyocytes and skeletal muscle fibres of the rat. Br J Pharmacol 172:4506-4518. https://doi.org/10.1111/bph.13235

Nánási P Jr, Gaburjakova M, Gaburjakova J, Almássy J (2017) Omecamtiv mecarbil activates ryanodine receptors from canine cardiac but not skeletal muscle. Eur J Pharmacol 809:73-79. https://doi. org/10.1016/j.ejphar.2017.05.027

Shen YT, Malik FI, Zhao X, Depre C, Dhar SK, Abarzúa P, Morgans DJ, Vatner SF (2010) Improvement of cardiac function by a cardiac myosin activator in conscious dogs with systolic heart failure. Circ Heart Fail 3:522-527. https://doi.org/10.1161/ CIRCHEARTFAILURE.109.930321

Shibata M, Takeshita D, Obata K, Mitsuyama S, Ito H, Zhang GX, Takaki M (2011) NHE-1 participates in isoproterenol-induced downregulation of SERCA2a and development of cardiac remodeling in rat hearts. Am J Physiol Heart Circ Physiol 301:H2154-H2160. https://doi.org/10.1152/ajpheart.00483.2011

Takaki M (2004) Left ventricular mechanoenergetics in small animal. Jpn J Physiol 54:175-207. https://doi.org/10.2170/jjphysiol.54.175

Teerlink JR (2009) A novel approach to improve cardiac performance: cardiac myosin activators. Heart Fail Rev 14:289-298. https://doi. org/10.1007/s10741-009-9135-0

Teerlink JR, Clarke CP, Saikali KG, Lee JH, Chen MM, Escandon RD, Elliott L, Bee R, Habibzadeh MR, Goldman JH, Schiller NB, Malik FI, Wolff AA (2011) Dose-dependent augmentation of cardiac systolic function with the selective cardiac myosin activator, omecamtiv mecarbil: a first-in-man study. Lancet 378:667-675. https://doi.org/ 10.1016/S0140-6736(11)61219-1

Zhang GX, Obata K, Takeshita D, Mitsuyama S, Nakashima T, Kikuta A, Hirabayashi M, Tomita K, Vetter R, Dillmann WH, Takaki M (2012) Evaluation of left ventricular mechanical work and energetics of normal hearts in SERCA2a transgenic rats. J Physiol Sci 62:221231. https://doi.org/10.1007/s12576-012-0200-4

Publisher's note Springer Nature remains neutral with regard to jurisdictional claims in published maps and institutional affiliations. 